\title{
In memory of Professor Giovanni Pizzuti
}

\author{
Emma Rabino Massa
}

Department of Life Sciences and Systems Biology, University of Turin, Italy

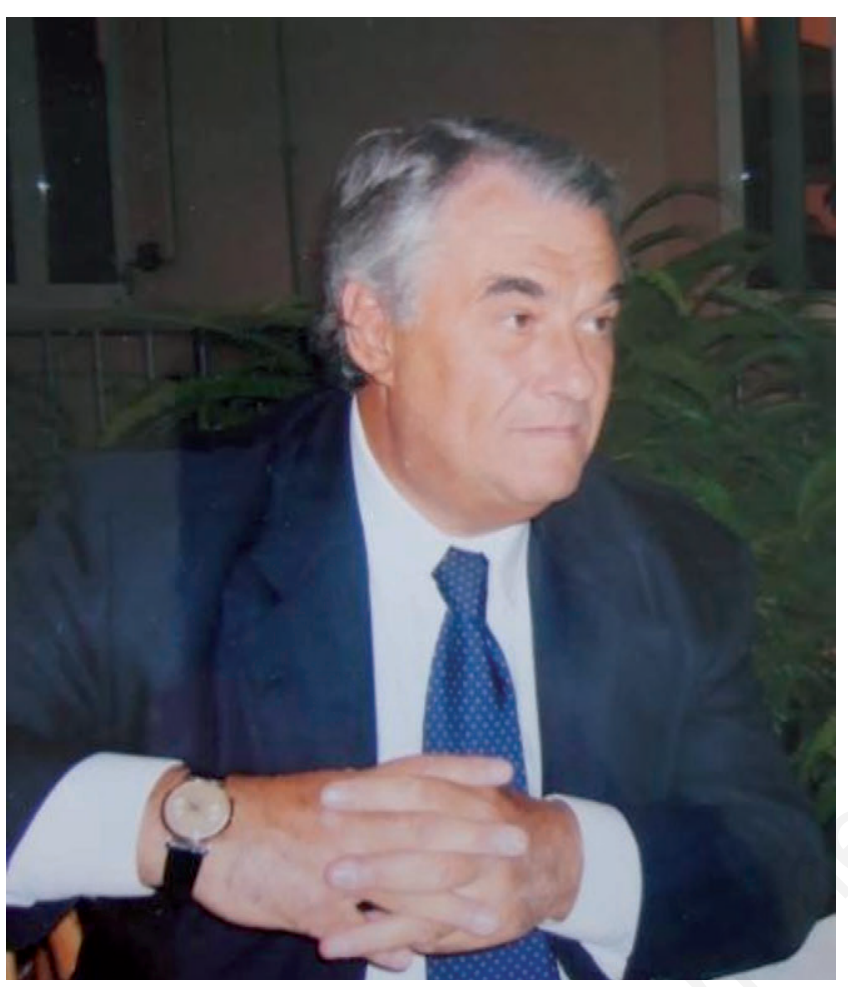

GIOVANNI PIZZUTI (Naples, 1945-2015)

Full Professor of Physiology, Faculty of Medicine, University of Naples Federico II

$\mathrm{PhD}$ in Biomedical Engineering

University of Surrey, Mechanical Engineering Faculty
The Italian Society for Experimental Biology (Società Italiana di Biologia Sperimentale, SIBS) regretfully commemorates Prof. Giovanni Pizzuti, who leaved a sharp mark in the Society's history, having fulfilled for many years the task of General Secretary with great effort and soundness.

Due to his professional activity as well as for his innovative research, he obtained important academic appreciation by Lincei National Academy (Accademia Nazionale dei Lincei), Royal Society, and British Council. After invitation by Prof. Byford he carried out research at the Institute of Aviation Medicine of the Royal Air Force (Fanbourg-Hants - England), contributing significantly to the research about the application of novel automatic methods in electrocardiography, and opening new prospects.

Notably, the research about the adoption of new methods to analyze signals for the study of the relationships between malnutrition and Central Nervous System electrical onthogenesis was innovative; this research, carried out at the Department of Engineering of the Trinity College (Hartford, Connecticut, USA), gave a fundamental contribution to the knowledge of neuronal plasticity. For these important studies, and for his scientific excellence, Prof. Pizzuti was admitted among members of the Society for Neuroscience (USA), of the British Ecological Society, and of Education Evaluators International.

I had the honour to collaborate with Prof. Pizzuti in the award of Ph.D. prizes of SIBS; in that occasion, I was able to recognize his large and never exhibited knowledge, and his scientific expertise in physiology, ecology, physics, and neurosciences.

If the scientific activity of Prof. Pizzuti is well documented by his publications, his ethical and human qualities, his style and warm willingness to colleagues and students are instead unforgettable and written in family, friends and colleagues hearts.

The SIBS expresses a deep sorrow for the loss of Prof. Pizzuti, whose contribution to the international development of the experimental biology has been fundamental.

In addition to the positive and fruitful cooperation a warm memory remains in myself.
Correspondence: Emma Rabino Massa, Department of Life Sciences and Systems Biology, University of Turin, Italy.

E-mail: emma.rabino@unito.it

Received for publication: 21 June 2019.

Accepted for publication: 24 June 2019.

CC Copyright E. Rabino Massa, 2019

Licensee PAGEPress, Italy

Journal of Biological Research 2019; 92:8352

doi:10.4081/jbr.2019.8352

This article is distributed under the terms of the Creative Commons Attribution Noncommercial License (by-nc 4.0) which permits any noncommercial use, distribution, and reproduction in any medium, provided the original author(s) and source are credited. 